\title{
Peningkatan Teknologi Pendidik Pesantren Anak Sholeh melalui MEMRiSE: Coaching \& Training
}

\author{
Hesty Puspita Sari ${ }^{*}$,Wawan Herry Setyawan ${ }^{2}$, Agus Budiman ${ }^{3}$ \\ 1 Universitas Islam Balitar, Blitar, Indonesia \\ 2Universitas Islam Kadiri, Kediri, Indonesia \\ ${ }^{3}$ Universitas Darussalam Gontor, Ponorogo, Indonesia \\ *Corresponding Author: hestypuspita1403@gmail.com
}

Info Artikel

Diterima : 01/06/2021

Direvisi: 02/07/2021

Disetujui: $12 / 07 / 2021$

\begin{abstract}
Mastering technology improvement is something that educators have to continue to strive for on an ongoing basis. A teacher is required to master the use and applicate the science and technology development along the revolution industrial era 4.0. To continue improving the quality of self, a teacher needs to be given coaching and training. The training activity with the theme "Introduction to English Language Learning Technology at the Pesantren Anak Sholeh, a kindergarden and primary school in Ponorogo" was attended by Ustadz and Ustadzah of the Pesantren Anak Sholeh for PAUD and Elementary School levels with a total of 12 participants. The coaching and training was carried out on Saturday, August 7, 2021 by introducing MEMRiSE as a very easy learning application that children can do to improve their English and Arabic vocabulary. Participants were given the opportunity directly to practice downloading and trying the MEMRiSE application and practice it. Based on the results of the activities, participants showed high enthusias $m$ in practicing the use of MEMRiSE and stated the ease of learning to increase children's vocabulary. In general, educators at the Sholeh Children's Islamic Boarding School have carried out creativity and learning innovation using MEMRiSE. The results of the responses from the coaching and training participants also showed $100 \%$ that MEMRiSE was motivating, fun for learning and very effective in learning trough online in the covid-19 pandemic situation.
\end{abstract}

Keywords: Technology, PAS,MEMRiSE

\begin{abstract}
Abstrak. Peningkatan kebutuhan penguasaan teknologi untuk tenaga pendidik adalah suatu keharusan yang seyogjanya terus diupayakan oleh pendidik secara berkelanjutan. Seorang pendidik dituntut untuk mampu menguasai dan mampu memanfaatkan perkembangan teknologi yang semakin canggih secara berkelanjutan selajan lajunya era revolusi industri 4.0. Untuk terus meningkatkan kualitas diri, seorang guru perlu dilakukan pembinaan dan pelatihan. Kegiatan Pelatihan bertema "Pengenalan Teknologi Pembelajaran Bahasa Inggris di Pesantren Anak Sholeh Ponorogo" diikuti oleh ustadz dan Ustadzah Pesantren Anak Sholeh jenjang PAUD dan Sekolah Dasar dengan jumlah 12 peserta. Pembinaan dan Pelatihan dilakukan pada hari sabtu, 7 Agustus 2021 dengan memperkenalkan MEMRiSE sebagai salah satu aplikasi pembelajaran yang sangat mudah dapat dilakukan anak anak untuk meningkatkan kosakata bahasa Inggris dan Arab. Peserta diberi kesempatan secara langsung untuk praktik mengunduh dan mencoba aplikasi MEMRiSE dan mempraktikkannya. Berdasarkan hasil kegiatan peserta menunjukkan antusias yang tinggi dalam mempraktikkan penggunaan MEMRiSE serta menyatakan kemudahan kemudahan belajar untuk meningkatkan kosakata anak anak. Secara umum, tenaga pendidik pada Pesantren Anak Sholeh telah melakukan kreatitifas dan Inovasi pembalajaran menggunakan MEMRiSE. Hasil respond peserta pembinaan dan pelatihan ini juga menunjukkan 100\% bahwa MEMRiSE memberi motivasi, menyenangkan untuk pembelajaran pada masa pandemi covid 19 karena sangat efektif dilakukan secara online.
\end{abstract}

Kata Kunci: Teknologi, PAS, MENRiSe

How to Cite: Sari,H. P., Setiawan, W.H. (2021). Peningkatan Teknologi Pendidik Pesantren Anak Sholeh melalui MEMRiSE: Coaching \& Training. Prima Abdika : Jurnal Pengabdian Masyarakat, 1(3), 81-90. https://doi.org/10.37478/abdika.v1i3.1123

Copyright (c) 2021 Hesty Puspita Sari,Wawan Herry Setyawan. This work is licensed under a Creative Commons Attribution-ShareAlike 4.0 International License.

\section{Pendahuluan}

Menjadi seorang pendidik pada masa ini dibutuhkan kecerdasan dan ketrampilan dalam mendayagunakan apapun yang dapat menjadi sumber belajar disekitar kegiatan pembelajaan, Era digital 4.0 memberi banyak peluang untuk pendidik meningkatkan ketrampilan memanfaatakan teknologi. Saat ini, bukan hal sulit untuk siswa megakses internet dan mendapatkan sumber belajar melalui media internet. Situasi ini mendorong 
pendidik untuk lebih cerdas dan berkreasi dalam mengembangkan dan menggunakan teknologi (Herry Setyawan et al., 2019). Karena siswa era saat ini adalah siswa yang canggih yang mampu mencari materi apa saja yang disamapaikan guru di internet. Mereka bahkan lebih cepat bergerak mendapatkan informasi tentang pelajaran disekolah dengan mengunduh di media internet. Disinilah posisi tenaga pendidik diharapkan lebih creative dan cermat dalam memilih dan memilah kemudian menyajikannya sebagai sumber belajar yang sesuai terhadap perkembangan anak didik. Guru dituntut secara sigap dapat mengakses pengetahuan pengetahuan secara online sebagai wujud kebaharuan dan kreatifitas tenaga pendidik dalam merepakan sistem pembelajaran yang baru dengan pemanfaatan teknologi sebagai sarana dan prasarana belajar siswa. Tidak hanya sekedar memanfaatkan teknologi, bahkan pendidik di harapkan mampu menerapkan aplikasi aplikasi pembajaran berbasis android ataupun berbasis website. Menurut M.Sutarno (April 2016) Teknologi semakin hari semakin berkembang. Kerakteristik ilmu pengetahuan dan teknologi adalah komponensial dimana ilmu pengetahuan akan berkembang dengan cepat, semakin lama semakin maju, mengalami perkembangan yang terus menerus, karena hasil dari tahap perkembangan akan menjadi landasan dan alasan untuk pengembangan langkah berikutnya (Rifai et al., 2020).

Tidak hanya pengajaran bahasa, semua pelajaran membutuhkan ketrampilan teknologi agar guru dan siswa tetap bisa berkomunikasi melakukan pembelajaran. Namun masih banyak pendidik yang belum mampu menghadapi era revolusi industry 4.0saat ini. Penyerapan teknologi dan pengmebangan nya juga belum 100\% dimiliki oleh seorang guru. Apalagi era ini didukung dengan keadaan pandemic yang berkepanjangan. Apabila pendidik tidak bergerak cepat melakukan perubaan dan pengembangan teknologi, maka tidak hanya ia yang tertinggal, namun juga siswa siswi nya akan tertinggal dan tergilas oleh zaman yang serba digital. Kegiatan pembelajaran juga akan tersendat karena tidak adanya kegiatan tatap muka. Sehingga kemampuan siswa pun akan sulit berkembang.

Dari hasil observasi yang dilakukan pada tanggal 5 agustus 2021 ditemukan bahwa pembelajaran bahasa pada Pesantren Anak Sholeh Ponorogo ini memiliki beberapa kelemahan. Diantaranya 1) Belum sepenuhnya menggunakna teknologi dalam pembelajaran bahasa inggris dan arab; 2) kreatiiftas guru kurang maksimal dalam penerapan teknologi; 3) kreatifitas pendidik dan siswa masih terbatas dalam penggunaan teknologi pembelajaran; 4) tidak semua walimurid mendukung kegiatan secara daring menggunakan teknologi karena mereka memiliki persepsi yang berbeda.

Melihat kondisi yang dihadapi pendidik pada Pesantren Anak Shole, diperlukan pendampingan dan pelatihan dalam pengembangan teknologi untuk diterapkan pada pembelajaran. Maka penulis tertarik untuk melakukan kegiatan pedampingan dan pelatihan peningkatan teknologi pendidik Pesantren Anak Sholeh menggunakan MEMRiSE dalam kegiatan Pengapdian kepada Masyarakat yang bertemakan "Pengenalan Teknologi Pembelajaran Bahasa Inggris bagi anak di Pesantren Anak Sholeh Ponorogo".

Media of learning is very effective to be applied in learning classes to improve students' vocabulary material (Sari \& Lestari, 2020). dengan menggunakan media pembelajaran, tenaga pendidik dan siswa akan lebih 
maksimal dalam melakukan pembelajaran. Untik meningkatan kemmapuan kosakata siswa diperlukan media yang menunjang keberhasilan peserta didik, dapat berupa media tradisional maupun media digital. Karena kemampuan pengusaan kosakata pada sisiwa akan mempengaruhi ketrampilan berbahasa. Banyaknya kosakata yang dimiliki seseorang akan menjadi dasar siswa tersebut dalam belajar bahasa. Menurut Jennah, (2009) diketahui dari bahasa latin "medius" pada hakikanya kata media yang secara harfiah memiliki makna: tengah, perantara, atau pengantar. Dalam bahasa arab media dimaknai sebagai perantara atau pengantar pesan dari pengirim kepada penerima pesan. Media berfungsi sebagai sarana ataupun perantara kesuksesan peserta didik dalam meningkatan kemampuan kosakata. Gerlach dan Ely dalam Arsyad, (2011) menyampaikan bahwa "media" secara garis besar dimaknai sebagai materi atau kejadian yang mendukung. Dimana kemampuan siswa atau siswi akan lebih termotivasi dan terangsang apabila dibantu dengan sejumlah media pembelajaran yang mendukung tercapainya tujuan pembelajaran. Dengan demikian "media pembelajaran" dapat dimaknai sebagai sarana yag memantu pelaksanaan pendidikan dalam ataupun diluar kelas. Dengan media guru dapat menyampaikan materinya dengan mudah dan siswa dapat memahami apa yang disampaikan guru, sehingga dapat merangsang perhatian, minat, pikiran dan perasaan peserta didik dalam melakukan kegiatan pembelajaran untuk mencapai tujuan pembelajaran yang telah disepakati. Media pembelajaran adalah penggunaaanya pada kegiatan pembelajaran sangat membantu keefektifan pelaksanaan kegiatan pembelajaran dan penyampaian materi/pelajaran, selain menumbuhkan semangat/motivasi dan minat peserta didik dalam belajar, media pembelajaran juga memiliki peran dalam membantu peserta didik meningkatkan pemahaman materi yang disampaikan dengan menarik dan terpercaya, memudahkan penafsiran materi, dan memadatkan informasi pembelajaran (Budiman \& Samani, 2021). Sehingga tenaga pendidik dapat memaksimalkan peserta didikdalam menggali potensi mereka.

Untuk mencapai keberhasilan pembelajaran, guru dapat menggunakan media sebagai sarana dan alat yang membantu memfasilitasi serta mendudkung ketercapaian tujuan pembelajaran Media pembelajaran bertujuan adalah untuk membantu menyampaikan kegiatan pembelajaran dan memfasilitasi komunikasi dan pembelajaran (Wati, 2019). Beberapa penelitian tentang media pembelajaran telah dilakukan dan didapakan beberapa kesimpulan dalam keberhasilan pengembangan alat pembelajaran berdasarkan android. Mobile learning atau pembelajaran berbasis android melonggarkan pemakai alat tersebut dalam kegiatan tanpa batasan waktu dan tempat. pengguna dapat melakukan kegiatan pembelajaran dengan aplikasi pada media android dimana saja dan akapan seja selama ada koneksi jaringan internet. Seperti yang disampaikan Klimova, (2018) an increasing trend has been arrised in the transition of the use of traditional technologies to the modern one like a desktop computer towards the use of mobile technologies trough a mobile phone where the student can study anywhere anythime as long as there is internet connection.

Terdapat 4 bagian yang perlu diperhatikan dalam pelaksaaan pembelajaran secara digital menurut Keane (2012), diantaranya 1) bahan ajar bersifat digital, 2) sarana digital, 3) ekspedisi digital, dan 4) Pembelajaran 
mandiri. Bahan ajar pengajaran secara digital dapat mengacu pada buku elektronik, data digital, atau materi materi yang tersajikan secara online lainnya. Dalam pelaksanaan kegiatan digilalisasi diperlukan alat alat yang mensupport keberhasilan pembelajaran secara digital dapat berupa: komputer desktop, komputer notebook, komputer tablet, dan smartphone/android. Agar kegiatan pembelajaran secara digital menuai keberhasilan maka perlu pengiriman digital yang berupa internet. Sifat dari digital learning sendiri adalah "otonom" dimana siswa focus pada kemandiriannya dalam kegiatan pembelajaran secara daring. Salah satu karakteristik pembelajaran online adalah penggunaan teknologi android. Teknologi android yang ditancapkan pada ponsel android. Ponsel android ini merupakan salah satu wadah pembelajaran yang lengkap, terbuka, dan gratis serta mudah dijangkau. Setyawan et al., (2018) dalam pembelajaran dan pengajaran, mobile learning Android dapat digunakan tidak hanya untuk dasar guru pengembangkan media pembelajaran tetapi juga dapat digunakan sebagai stimulus siswa agar termotivasi belajar dalam masa masa lockdown saat ini dimana guru dan siswa terbatas dalam bertatap muka.

Media digital yang dapat diaplikasikan pada kegiatan pengabdian kepada masyarakat ini adalah MEMRiSE yang dapat $d$ unduh langsung melalui play store pada media android. Apabila guru belum mampu mengembangakan media pembelajaran berbasis android maka pembelajaran akana sangat menyenangkan namun saat ini sudah banyak sekali aplikasi pembelajaran mulai yang berbayar hingga yang gratis pada android. Pendidik cukup memanfaatkannya untuk pembelajaran. Salah satu aplikasi pembelajaran gratis yang dapat dimanfaatkan adalah MEMRiSE. MEMRise menawarkan pembelajaran tidak hanya untuk bahasa inggris, tetapi juga arab, Spanish, jepang dll. Keunggulan Memrise terletak pada strategi pembelajarannya yang mendukung, menyenangkan, mudah dipahami, dapat diakses secara intensif dan fleksibel dengan m-learning, serta melatih kemahiran mendengar, membaca dan menulis dengan baik, sementara kelemahannya adalah Memrise masih berbasis daring (Fajrina et al., 2017). Innovation in learning is supported by learning strategies and the application of media in learning avtivity such MEMRiSE is very significant to create effective and creative English language learning, especially the current situation of COVID-19 pandemic (Melati \& Herlina, 2019). Memrise is an application which can be found in an android has improved the student's mastery of irregular verbs (Rosydah, 2018); (W. H. Setyawan \& Nawangsari, 2021).

\section{Metode Pelaksanaan}

Kegiatan Pengabdian Kepada Masyarakat ini dikuti oleh ustadz dan ustadzah pada Pesantren Anak Sholeh Ponorogo terdiri dari 12 Peserta. Kegiatan ini telah dilaksanakan secara face to face tanpa melupakan penerapan disiplin kesehatan yang ketat dengan mencucui tangan, menggunakan masker, serta tempat duduk yang sudah berjarak. Perlengkapan yang digunakan dalam kegiatan Pengabdian ini meliputi Power Point, google form, WhatsApp, email, dan alat tulis menulis. Kegiatan ini dilaksanakan secara tatap muka di gedung Indonesia 2 lantai 2 Pesantren Anak Sholeh Ponorogo tanggal 7 Agustus 2021 untuk penyampaian materi kemudian ustadz dan ustadzah dipersilahkan untuk menerapkan aplikasi 
tersebut kepada peserta didik selama seminggu,dan pada tanggal 14 peneliti mengirimkan google form respon penggunaan aplikasi MEMRiSE. Tabel 1 memperlihatkan rangkaian kegiatan secara rinci.

Tabel 1. Agenda Kegiatan Pengabdian

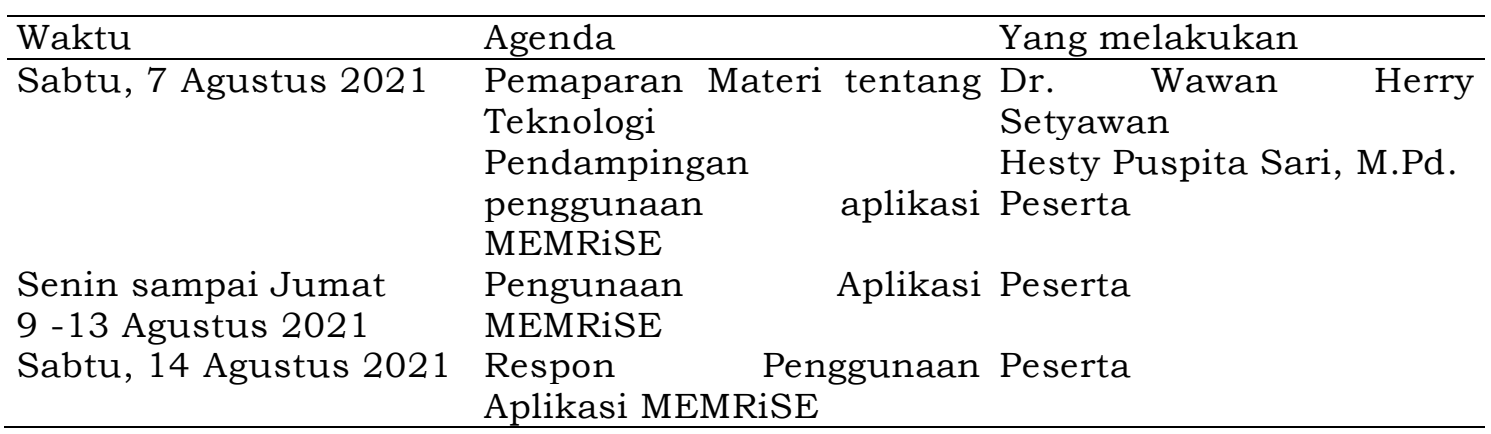

\section{Hasil dan Pembahasan}

Materi disampaikan dalam 2 sesi. Sesi pertama tentang Teknologi dan sesi kedua tentang aplikasi teknologi.

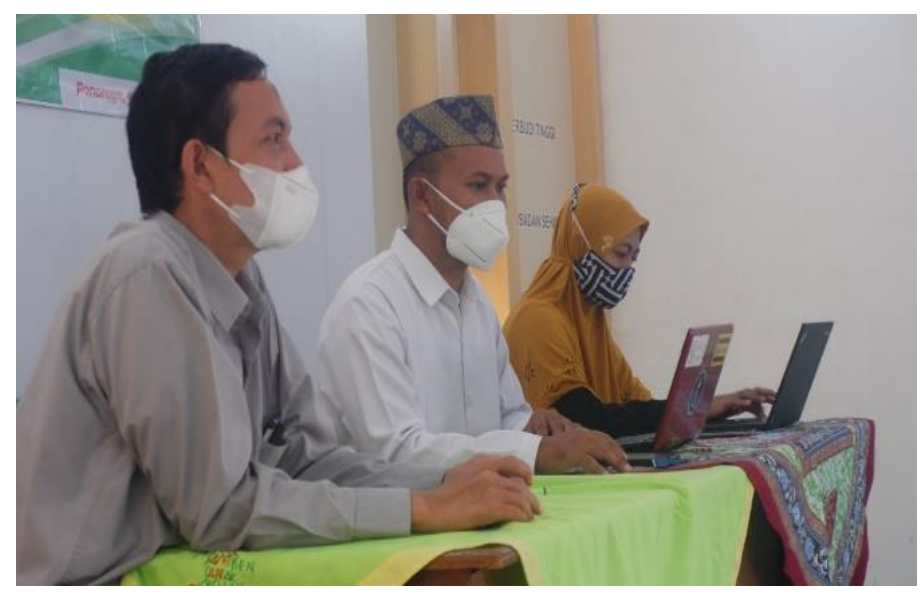

Gambar 1. Pemateri

Pemaparan materi tentang pengenalan Teknologi Pembelajaran Bahasa Inggris Bagi anak disampaikan oleh Dr. Wawan Herry Setyawan, S.Pd., M.Pd. Materi yang disampaikan adalah tentang pentingnya teknologi dalam pembelajaran Inggris terutama selama masa pandemic. Dengan bekal pengguasaan teknologi, pendidik dapat maksimal melakukan pembelajaran secara daring. Selain itu pemateri juga menyampaikan secara umum tentang pemahaman konsep pembelajaran pemula, dan aktifitas belajar mengajar yang menyenangkan dan efektif untuk peserta didik usia dini dalam menguasai bahasa asing yakni bahasa Inggris.

Berdasarkan hasil evaluasi, didapatkan hasil peserta memahami konsep pembelajaran anak usia dini dan macam macam kegiatan yang menarik yang dapat diterapkan pada kelas anak usian dini sesuai kemampuan anak didik dalam mengembangkan bahasa. Akhirnya Bapak ibu guru mendapatkan pemahaman yang lebih dan metode yang tepat serta cara cara yang menarik dalam meningkatkan pengguasaan bahasa inggris peserta didik. Output dari 
pemaparan ini adalah pemahaman peserta didik tentang pentingny a penguasaan teknologi sebagai dasar pelaksaan pembelajaran pada Pesantren Anak Sholeh.

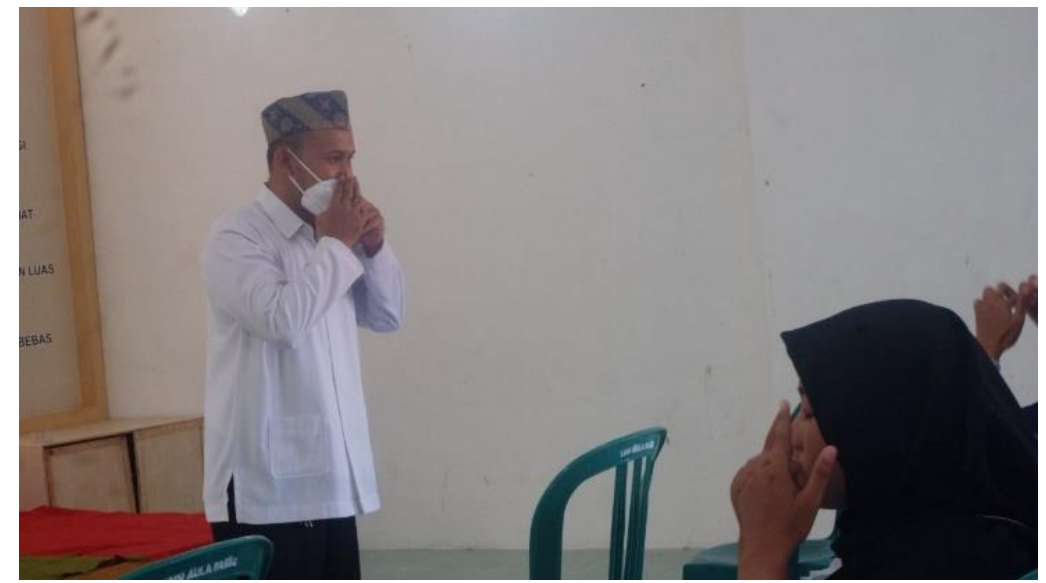

Gambar 2. Kegiatan pengenalan teknologi

Pemaparan Materi yang kedua disampaikan oleh Hesty Puspita Sari, M.Pd. materi yang di sampaikan adalah Penggunaan aplikasi MEMRiSE dalam meningkatkan penguasaan kosakata siswa.

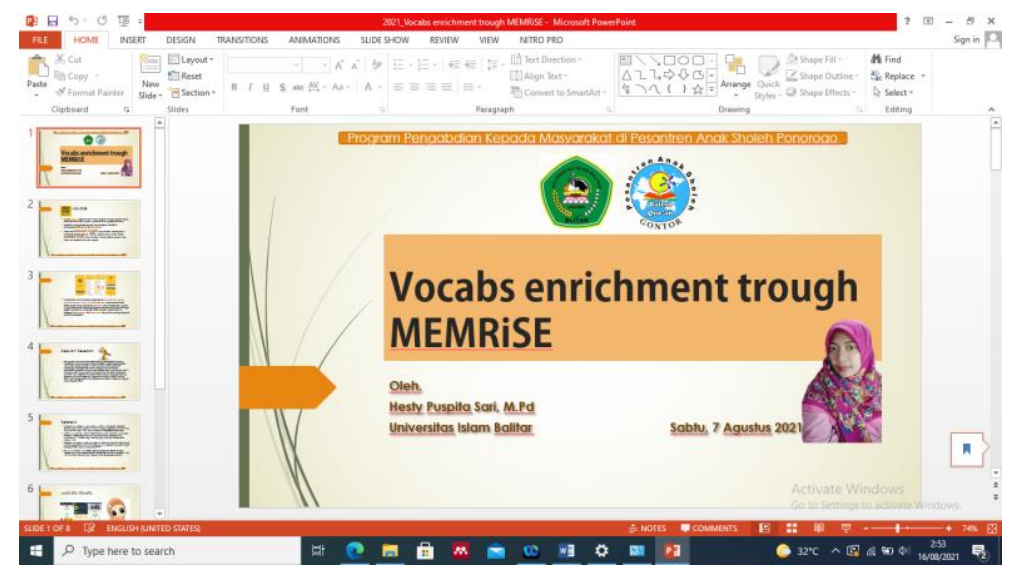

Gambar 3. Materi tentang MEMRiSE

Pemateri mengajak peserta kegiatan untuk mengunduh aplikasi MEMRiSE pada play store dan mempraktikkannya secara langsung. Peserta terlihat sangat antusias mempraktikkan penggunaan aplikasi MEMRiSE, terlihat setiap peserta mempraktikkan secara langsung. Bahkan mereka tidak hanya mencoba MEMRiSE untuk pembelajaran Bahasa Inggris maupun bahasa Arab, beberapa melakukan percobaan dengan pembelajaran bahasa Jerman, Jepang, bahkan korea. Outpun dari kegiatan ini adalah peserta memahami salah satu aplikasi yang dapat digunakan untuk meningkatkan kosakata anak terutama dalah Bahasa Inggris dan Bahasa Arab yaitu aplikasi MEMRiSE. Peserta didik dapat mengaplikasikannya pada pembelajaran di Pesantren Anak Sholeh sebagai wujud dari kreatifitas pembelajaran secara daring. 


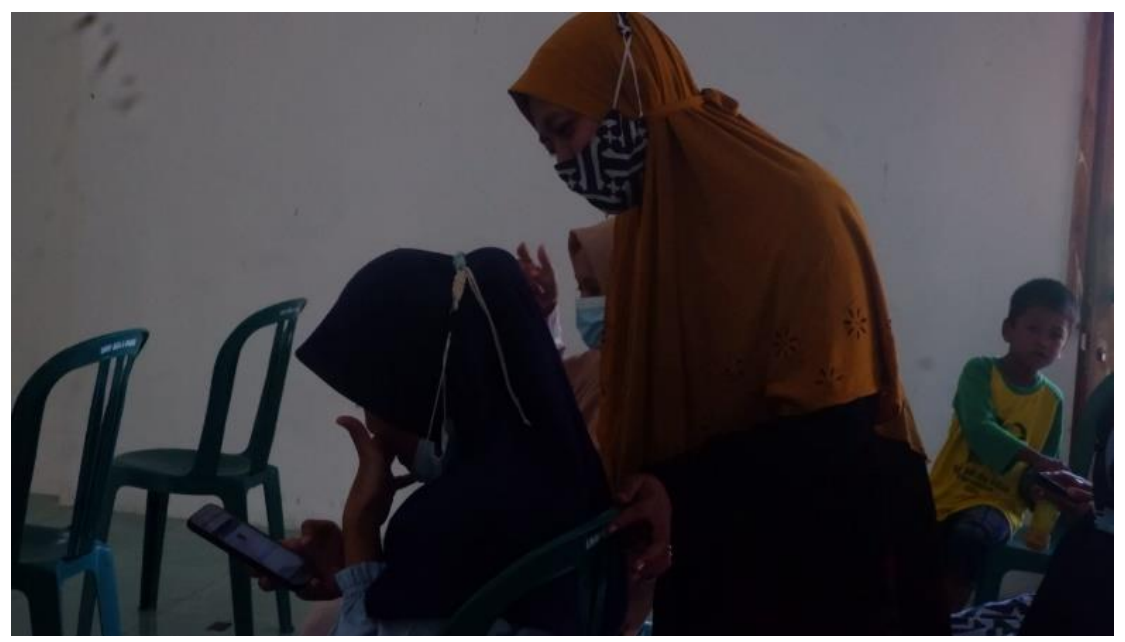

Gambar 4. Peserta melakukan praktik penggunaan aplikasi MEMRiSE

Setelah kegiatan pemaparan selesai dilaksanakan, peserta kegiatan mendapatkan kesempatan untuk mengaplikasikannya pada kegiatan pembalajaran kepada peserta didik pada kelasnya masing masing secara daring. Selama beberapa hari peserta melakukan penerapan aplikasi MEMRiSE tersebut menyampaikan bahwa siswa/siswi sangat senang dan antusias belajar menambah kosakata Bahasa Inggris mereka dengan mengunakan aplikasi Memrise. Setelah 5 hari menenrapkan pembelajaran peningkatan kosakata peserta didik secara daring menggunakan MEMRiSE diketahui bahwa peserta didik sangat senang dengan pembelajaran menggunakan MEMRiSE dan ustadz ustadzah pun menyampaikan bahwa:

1. $100 \%$ menjawab bahwa MEMRiSE mudah diunduh dan ukurannya kecil sehingga tidak membebani adroid

2. 91,7\% menyatakan bahwa MEMRiSE mudah digunakan oleh peserta didik karena anak anak sudah terbiasa mengunakan android untuk bermain sehingga apabila digunakan untuk belajarpun mereka sudah sudah familiar

3. $100 \%$ menyampaikan MIEMRiSE memberi motivasi belajar bahasa karena tampilannya yang sederhana

4. $100 \%$ menjawab MEMRiSE sangat menyenangkan untuk pembelajaran bahasa karena anak dapat belajar dari penutur aslinya.

5. $100 \%$ menjawab MEMRiSE sangat efektif dan efisien diaplikasikan saat ini dimasa pandemic saat guru tidak bisa secara langsung berinteraksi dengan siswa. 


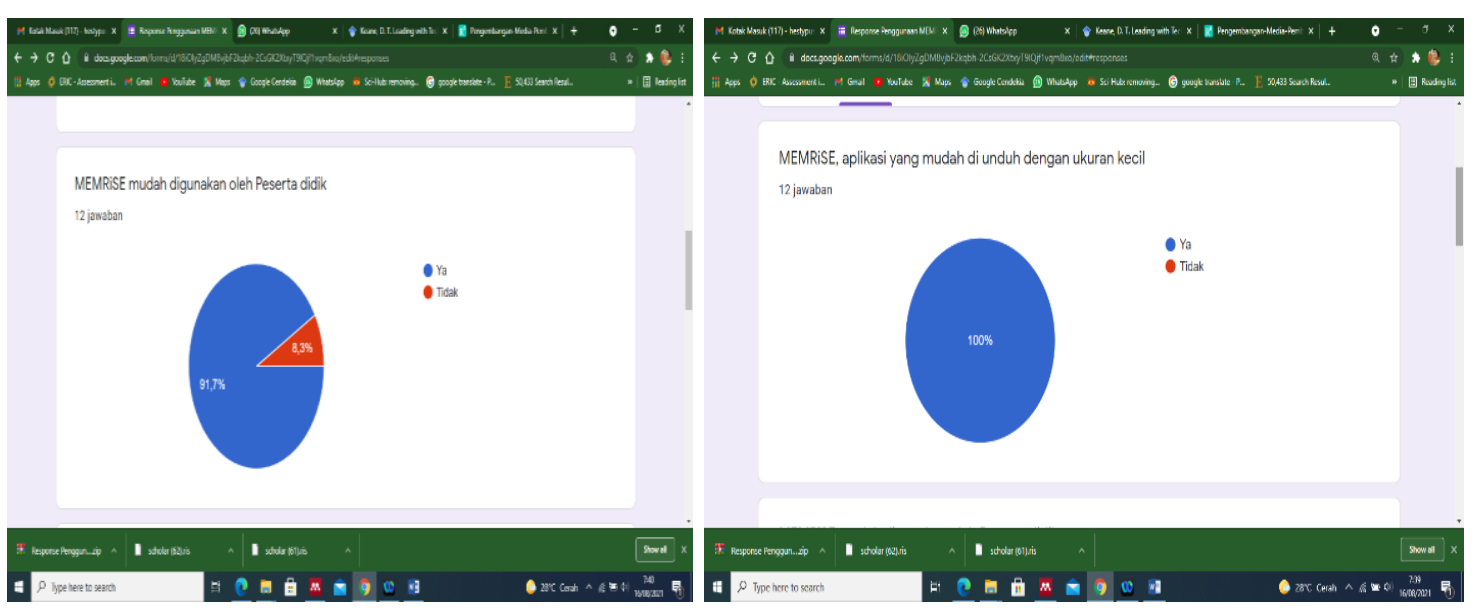

\section{Simpulan dan Tindak Lanjut}

Kegiatan Pengabdian kepada masyarakat ini memiliki harapan untuk ikut meningkatkan kemampuan guru dalam bidang teknologi dengan mengenalkan aplikasi MEMRiSE yang terdapat pada android untuk digunakan dalam meningkatkan kegiatan pembelajaran bahasa Inggris di Pesantren anak Sholeh Ponorogo. Khususnya melakukan pembinaan dan Pelatihan kepada tenaga pendidik di Pesantren anak sholeh untuk menerapkan MEMRiSE dalam mengembangkan kemampuan kosakata siswa. Dengan kemampuan kosakata maka kemampuan bahasa siswa akan meningkat.

Saptaria \& Setyawan (2021) dengan memanfaatkan pengenalan teknologi pada Kegiatan Pengabdian kepada masyarakat dapat meningkatkan motivasi warga pendidikan serta mendapakan penghargaan yang besar dari pimpinan Pesantren anak sholeh karena menunjukkan hasil yang signifikan dimana peserta memahami konsep dan prinsip pembelajaran bahasa Inggris di lingkup PAUd dan sekolah dasar, yang meliputi materi, metode, media, dan kegiatan pembelajaran. Dengan di pahaminya aplikasi MEMRiSE, peserta kegiatan dapat mengaplikasikannya pada anak didik dalam pembelajaran kosakata. Sehingga peserta kegiatan mampu mencipkatan suasana yang menyenangkan dalam pembelajaran meskipun dimasa pandemic. Pun setelah dilakukan ujicoba penggunaaan aplikasi MEMRiSE pada peserta didik didapati hasil yang sangat memuaskan dimana MEMRiSE membantu peserta didik dalam meningkatkan kosakata berbahasa mereka secara efektif dan efesien.

\section{Daftar Pustaka}

Arsyad, A. (2011). Media pembelajaran. Jakarta: PT Raja grafindo persada.

Budiman, A., \& Samani, M. (2021). The Development of Direct-Contextual Learning: A New Model on Higher Education. International Journal of Higher Education, 10(2), 15-26. https://doi.org/doi:10.5430/ijhe.v10n2p15

Fajrina, C. M., Mutaali, A., \& Triwinarti, W. (2017). Pengayaan kosakata bahasa Arab melalui program memrise = Arabic vocabulary enrichment by using memrise. 
Herry Setyawan, W., Budiman, A., Septa Wihara, D., Setyarini, T.,

Nurdyansyah, Rahim, R., \& Barid Nizarudin Wajdi, M. (2019). The effect of an android-based application on T-Mobile learning model to improve students' listening competence. Journal of Physics: Conference Series, 1175, 012217. https://doi.org/10.1088/1742-6596/1175/1/012217

Jennah, R. (2009). Media Pembelajaran. Antasari Press.

Keane, T. (2012). Leading with technology: 21 st century skills $=3 \mathrm{Rs}+4 \mathrm{Cs}$. Australian Educational Leader, 34(2), 44.

Klimova, B. (2018). Mobile phones and/or smartphones and their apps for teaching English as a foreign language. Education and Information Technologies, 23(3), 1091-1099.

Melati, M., \& Herlina, H. (2019). Optimizing EIL Using "Memrise" As A Builder Students' Vocabularies. Edu-Ling: Journal of English Education and Linguistics, 3(1), 190-206. https://doi.org/https://doi.org/10.32663/eduling.v3i1.1315

Rifai, M., Masitoh, S., Bachri, B. S., Setyawan, W. H., Nurdyansyah, N., \& Puspitasari, H. (2020). Using Electronic Design Automation and Guided Inquiry Learning Model in Higher Engineering Education. Universal Journal of Educational Research.

https://doi.org/10.13189/ujer.2020.080723

Rosydah, E. C. (2018). Improving student's mastery of Irregular Verb by using Memrise application at the tenth grade of MAN Sidoarjo. UIN Sunan Ampel Surabaya.

Saptaria, L., \& Setyawan, W. H. (2021). Desain Pembelajaran

Technopreneurship Untuk Meningkatkan Motivasi Berwirausaha Mahasiswa Uniska Kediri. Prima Magistra: Jurnal Ilmiah Kependidikan, 2(1), 77-89. https://doi.org/https://doi.org/10.37478/jpm.v2i1.880

Sari, H. P., \& Lestari, W. D. (2020). Designing Superlary Game to Learn Vocabulary of Tenth Grade Students. EDUCATIO: Journal of Education, 5(2), 159-168.

https://doi.org/https://doi.org/10.29138/educatio.v5i2.296

Setyawan, W. H., \& Nawangsari, T. (2021). Pengaruh E-Module Speaking Berbasis Website Untuk Meningkatkan Keterampilan Berbicara. Aksara: Jurnal Ilmu Pendidikan Nonformal, 7(2), 339-346. https://doi.org/http://dx.doi.org/10.37905/aksara.7.2.339-346.2021

Setyawan, W., Rusijono, M., \& Jannah, M. (2018). T-Mobile Learning Android Model-Based to Improve Students' Listening Capability. Proceedings of the 1st International Conference on Education Innovation (ICEI 2017). https: / / doi.org/10.2991/icei-17.2018.96 
Wati, E. R. (2019). Ragam media pembelajaran.

\section{Ucapan Terima Kasih}

Peneliti mengucapkan terimakasih yang luar biasa tak terhingga kepada yang terhormat Bapak Dr. Drs. H. Soebiantoro, M.Si sebagai Rektor Universitas Islam Balitar Blitar, Ibu Devita Sulistiana, S.Si, M.Pd, sebagai Dekan FKIP UNISBA, keluarga Pesantren Anak Sholeh Ponorogo, Ustadz Dr. H. Agus Budiman, M.Pd. dan juga seluruh teman teman yang terlibat membantu terlaksananya kegiatan ini.

\section{Biodata Anggota Tim}

Hesty Puspita Sari, M.Pd adalah dosen Pendidkan Bahasa Inggris pada Program Studi pendidikan bahasa Inggris FKIP, Universitas Islam Balitar, Blitar, Indonesia. Sangat senang dengan sesuai tang menantang dan baru, menyukai pengembangan pengembangan media untuk dunia pendidikan anak serta sangat senang dengan Penelitian dan Pengembangan Bahasa Inggris pada anak usia dini.

Dr. Wawan Herry Setyawan dosen bahasa Inggris dan ilmu pendidikan pada program studi Pendidikan Bahasa Inggris, Universitas Islam Kadiri, Kediri. Aktif menulis dalam berbagai media dan senang melakukan pemanfaatan teknologi serta didiseminasikannya pada sekolah sekolah. 